\title{
Increasing HIV testing among hard-to-reach groups: examination of RAPID, a community-based testing service in Queensland, Australia
}

\author{
Allyson J. Mutch ${ }^{1 *}$, Chi-Wai Lui ${ }^{1}$, Judith Dean ${ }^{1}$, Limin Mao ${ }^{2}$, Jime Lemoire ${ }^{3}$, Joseph Debattista ${ }^{4}$, Chris Howard $^{3}$, \\ Andrea Whittaker ${ }^{5}$ and Lisa Fitzgerald ${ }^{1}$
}

\begin{abstract}
Background: The success of 'treatment as prevention' (TasP) to control HIV relies on the uptake of testing across priority population groups. Innovative strategies including; rapid HIV testing (RHT) in community and outreach settings, engaging peer service providers, and not requiring disclosure of sexual history have been designed to increase access. This paper reports on the implementation of 'RAPID', a community-based testing program in Queensland, Australia that employs these strategies to increase access to testing.
\end{abstract}

Methods: Service data, including client registration forms and a satisfaction survey from all clients attending RAPID between August 2014 and July 2015 were analysed.

Results: In 2014/2015 1,199 people attended RAPID to receive a free HIV test. The majority were urban-based gay men. $17.1 \%$ were first-time testers and $20.1 \%$ of participants were not eligible to access Medicare, Australia's universal health care scheme.

Conclusions: RAPID's evidence-based strategies appear to facilitate access to HIV testing, particularly among those who have never tested before; however the implications for the ongoing treatment and care of people ineligible for Medicare, who test positive to HIV warrants careful consideration.

Keywords: HIV testing models, STI, Treatment as prevention, Peer led, Rapid testing

\section{Background}

Early diagnosis and rapid initiation of antiretroviral therapy (ART) is a key strategy in the control of the global HIV/AIDS epidemics [1]. Earlier access to testing for HIV and subsequent uptake of ART can improve health outcomes of people living with HIV (PLHIV), potentially eliminating the risk of HIV transmission and reducing HIV notification rates at a population level [2]. The Joint United Nations Programme on HIV/AIDS (UNAIDS) now considers regular testing and early treatment uptake critical components of the 'treatment as prevention' (TasP) strategy for HIV risk reduction [3].

\footnotetext{
* Correspondence: a.mutch@sph.uq.edu.au

${ }^{1}$ The School of Public Health, The University of Queensland, Brisbane, Queensland, Australia

Full list of author information is available at the end of the article
}

The success of TasP relies on the uptake of testing and treatment across priority population groups in the community $[4,5]$. Over the last decade, some countries have seen an increase in HIV testing rates [6], but within Australia rates have remained relatively constant with less than two-thirds of gay men meeting current minimum recommendations to test every 12 months [7]. Beyond gay communities, rates of HIV testing among groups that have traditionally been hard-to-reach with conventional venepuncture testing [8], including young people and people from culturally and linguistically diverse backgrounds, are largely unknown [9].

Many barriers undermine the uptake of HIV testing at both the individual (e.g., fear, stigma, perceptions of risk, embarrassment in talking with health professionals) and health service level (e.g., testing location, wait time for 
results, cost) [8, 10-13]. In response, researchers and service providers have introduced and evaluated innovative approaches and strategies designed to facilitate access to testing. These include the adoption of rapid HIV testing (RHT) technology, use of community and outreach settings for testing, use of peer services, and establishing testing services that do not require the disclosure of sexual history $[8,10,14]$. The following paper reports on the implementation of 'RAPID', a novel RHT program developed in Queensland, Australia that has employed a mix of the above-mentioned strategies to increase access to HIV testing.

\section{Design and characteristics of the RAPID program}

In Queensland, and across Australia, the incidence of HIV has continued to increase with the rate of HIV diagnosis per 100,000 rising from 4.4 to 5.1 between 2009 and 2013: in 2013 there were 236 new cases of infection [15]. In a commitment to TasP, the Queensland State Government adopted RHT technology in 2013, following its approval for use in Australia in 2011 [16, 17]. Community-based testing services such as 'Testing Point' established by the Queensland AIDS Council, and the 'RAPID' testing program, established in August 2014 under the auspice of Queensland Positive People (QPP) in partnership with the HIV Foundation of Queensland, have been instrumental in the roll out of RHT in Queensland. Over half the RHT performed in Queensland in the first quarter of 2015 were conducted at community sites through programs such as RAPID [18].

In comparison with conventional venepuncture testing which requires a trained clinician to take a blood sample and forward it on for laboratory testing, RHT is a cost effective method of testing [19] that produces results in around $20 \mathrm{~min}$ at the point of care without the need for clinical supervision or laboratory analysis [20]. Studies comparing RHT with standard testing have found most participants prefer RHT, identifying it as more comfortable, convenient and less stressful [14, 21-23]. Table one provides a summary of the comparisons between community-based RHT services, such as RAPID and clinical services offering conventional HIV testing. Table 1

RAPID's service model draws on an emerging evidence base that indicates locating RHT in non-clinical, community and outreach settings (e.g., shopfronts during festivals, sex on premise venues (SOPV)) can increase access among people who have never tested or tested infrequently [13, 21, 22, 24-26]. Concerns have been raised over issues of confidentiality and professionalism when testing in SOPVs [11, 13], but evidence of high levels of user satisfaction [11] and increased access for hard-toreach groups [13, 26-29], particularly in comparison with

Table 1 Comparisons between community-based RHT and clinical services offering conventional HIV testing in Queensland

\begin{tabular}{|c|c|c|}
\hline & Community-based Peer Testing Services e.g., RAPID & Public Sexual Health Service (PSHS) or Primary Care Provider \\
\hline HIV test available & RHT & $\begin{array}{l}\text { Conventional whole blood sample testing (RHT available } \\
\text { in some PSHS) }\end{array}$ \\
\hline $\begin{array}{l}\text { Who performs HIV pre-test } \\
\text { information and test }\end{array}$ & Trained Peer Testing Facilitator (LGBTQI+ people) & $\begin{array}{l}\text { Clinician (e.g., Specialist Sexual Health/HIV Registered } \\
\text { Nurses (RN), Sexual Health Physician/HIV Specialist or GP) }\end{array}$ \\
\hline \multicolumn{3}{|l|}{ Results Waiting time } \\
\hline RHT & In-house & In-house \\
\hline Conventional & & Off-site at public pathology service \\
\hline Confirmatory HIV testing & $\begin{array}{l}\text { If the test is RHT reactive -conventional HIV test } \\
\text { performed by Trained Peer Testing Facilitator } \\
\text { and specimen sent to private pathology service } \\
\text { for analysis }\end{array}$ & Analysis performed on initial whole blood sample \\
\hline Confirmed HIV positive & $\begin{array}{l}\text { Referred off-site to PSHS or GP of clients choice } \\
\text { for HIV care }\end{array}$ & HIV care provided on-site ${ }^{b}$ \\
\hline Appointment/Walk-in & Walk-in & Appointment $+/$ - walk-in for symptomatic \\
\hline Location & Community sites, SOPVs, LGBTQI+ events & Clinics and GP practices \\
\hline Cost of service to clients & Free & $\begin{array}{l}\text { PSHS free, GP may require a co-payment in addition to } \\
\text { Medicare }^{a} \text { fee }\end{array}$ \\
\hline Cost to Health System & $\begin{array}{l}\text { Cost effective population testing, but more } \\
\text { expensive for HIV reactive results because } \\
\text { requires additional test }\end{array}$ & $\begin{array}{l}\text { Less cost effective for population screening than } \mathrm{RHT} \text {, } \\
\text { but for those receiving a positive result it is cheaper } \\
\text { than community-based RHT }\end{array}$ \\
\hline $\begin{array}{l}\text { Pre-test information and sexual } \\
\text { health history }\end{array}$ & $\begin{array}{l}\text { Often do not take full history, but provide } \\
\text { education while waiting for results }\end{array}$ & Full sexual history generally standard practice \\
\hline
\end{tabular}


conventional testing located in clinical settings, were central drivers for RAPID.

Lornec and colleagues' systematic review of testing preferences highlighted the need for testing services that are: "community-based, friendly, culturally competent, gay positive and that normalised sexuality and STD/HIV testing" [10]. In line with this, RAPID developed a peer-based service that relies on trained community members to provide testing and education services. Evidence suggests this can be an effective strategy designed to create a friendly and comfortable environment $[30,31]$ that may increase engagement among those who have not previously tested or those who have felt stigmatised in clinical settings $[25,26,32]$. The peer model also allowed RAPID to step beyond traditional clinical assessment methods, which emphasise sexual behaviour and history taking, to further reduce barriers and 'normalise' HIV testing [33, 34].

In sum, RAPID adopted all of the strategies identified by current best evidence to provide an accessible service designed to increase HIV testing, particularly among those who had never tested for HIV. The following paper examines the characteristics of people who attended RAPID and tested for the first time to consider the extent to which RAPID met its objectives.

\section{Methods}

This paper analysed service data gathered from all clients attending RAPID between August 2014 and July 2015. The data gathered by RAPID included a registration form, client satisfaction survey and an attendance log. The registration and client satisfaction forms were developed based on RAPID's philosophy of 'testing without the full Q\&A', thus questions were kept to a minimum (20 items). The self-complete registration form included age, gender, sexual orientation, country of birth, Medicare card (yes/no), postcode, and how the client heard about RAPID Additional file 1.

The client satisfaction survey, self-completed at the end of the visit, collected HIV testing history and reason for testing on this occasion, and satisfaction with the RAPID service. The attendance log recorded information on testing venue (RAPID main clinic or SOPV), people who returned for one or more tests, and people who were HIV reactive.

Ethics approval for the study was obtained from the Metro North Hospital and Health Service and The University of Queensland Human Research Ethics Committee (Approval No. 2015001063).

\section{Data analysis}

Data were analysed using SPSS ${ }^{\mathrm{TM}}$ software (Version 22, Statistical Software for Social Sciences, IBM, Chicago). Descriptive statistics (means, standard deviations, frequencies, per cents) were performed on all client characteristic variables. The sample was then divided and data summarised and compared based on whether a person had ever tested for HIV. A significance level of $P<0.05$ was used for all tests.

\section{Results}

One thousand four hundred eighty-four RHTs, involving 1,199 people, were conducted by RAPID between August 2014 and June 2015. The following results are based on the person's first visit to RAPID or its outreach services at SOPVs and excluded those attending for an additional test(s) (Table 2). The majority of clients were men (95.4\%) who identified as gay or bisexual (85.1\%). The mean age was 34.9 and most $(81.1 \%)$ lived in the

Table $\mathbf{2}$ Characteristics of all RAPID Clients and First-time Testers

\begin{tabular}{|c|c|c|}
\hline & $\begin{array}{l}\text { All RAPID Clients } \\
n=1199(\%)^{\mathrm{a}}\end{array}$ & $\begin{array}{l}\text { First-time Testers } \\
n=191(17.1 \%)\end{array}$ \\
\hline \multicolumn{3}{|l|}{ Gender } \\
\hline Male & $1144(95.4)$ & $170(89.0)$ \\
\hline Female & $53(4.4)$ & $21(11.0)$ \\
\hline Transgender & $2(0.2)$ & 0 \\
\hline \multicolumn{3}{|l|}{ Age } \\
\hline Mean (Standard Dev) & $34.9(12.9)$ & $30.8(13.6)$ \\
\hline Range & $17-83$ & $18-83$ \\
\hline \multicolumn{3}{|l|}{ Sexuality } \\
\hline Gay/Bi-sexual & $1017(85.0)$ & $133(69.6)$ \\
\hline Straight & $179(15)$ & $58(30.4)$ \\
\hline Indigenous & $26(2.2)$ & $2(1.0)$ \\
\hline \multicolumn{3}{|l|}{ Country of Birth } \\
\hline Australia & $717(59.8)$ & $96(50.3)$ \\
\hline Other & $481(40.2)$ & $95(49.6)$ \\
\hline \multicolumn{3}{|l|}{ Residential location } \\
\hline Urban & $935(81.1)$ & $147(79.5)$ \\
\hline Regional/Rural & $129(11.2)$ & $25(13.5)$ \\
\hline Other & $89(7.7)$ & $13(7.0)$ \\
\hline \multicolumn{3}{|l|}{ Testing Venue } \\
\hline RAPID Clinic & $885(78.2)$ & $149(80.1)$ \\
\hline SOPV & $247(21.8)$ & $37(19.9)$ \\
\hline \multicolumn{3}{|l|}{ Ever Tested } \\
\hline Yes & $927(82.9)$ & - \\
\hline No & $191(17.1)$ & - \\
\hline \multicolumn{3}{|l|}{ Frequency of testing } \\
\hline Within the last 12 months & $619(55.4)$ & - \\
\hline More than 12 months ago & $308(27.5)$ & - \\
\hline First time & $191(17.1)$ & 191 (100.0) \\
\hline Medicare Ineligible & $241(20.1)$ & $57(29.8)$ \\
\hline
\end{tabular}

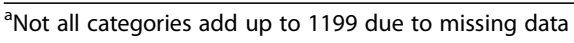


greater Brisbane area. Over half $(59.8 \%)$ were born in Australia with the remainder representing over 70 different countries. One in five people (20.1\%) attending RAPID were not eligible to access Medicare, Australia's universal health care scheme that covers core health service costs. The majority of these individuals were born overseas (91.7\%:221).

Twenty-one men (1.8\%) received a reactive HIV test result which was confirmed with subsequent clinical testing. The majority attended the main RAPID testing site with four (1.6\%) people tested at an SOPV. Most of the people who received a reactive result identified as gay or bisexual (95.2\%:20), living in the greater Brisbane area $(76.2 \%: 16)$ and approximately half were born in Australia (47.6\%:10). Frequency of testing was poorly reported amongst the sub-sample of people testing positive for HIV with only four people indicating that they had been tested in the last year. Six (28.6\%) people who tested positive were Medicare ineligible.

\section{First-time testers}

One hundred ninety-one (17.1\%) people had never previously tested for HIV and were tested for the first-time at RAPID. The majority of first-time testers were men (89.0\%: 170). First-time testers were significantly younger ( $\mathrm{X}=30.86$ years $)$ than previous testers $(\mathrm{X}=35.94$ years $)$ $(\mathrm{t}=-4.76(261) \quad P<0.05)$ and $40 \%$ of women visiting RAPID were testing for the first time compared with only $14.9 \%$ of men $\left(X^{2}=22.85\right.$ (1) $\left.P<0.05\right)$. The majority of first-time testers visited the main testing centre; there was no association between testing venue and having ever tested for HIV. First-time testers were significantly more likely to be Medicare ineligible (29.8\%: 57) compared to those who had previously tested (17.2\%:159) $\left(X^{2}=16.36(1), P<0.05\right)$. People who had never tested were significantly more likely to identify as straight $(30.4 \%$ : 58$)$ when compared to people who had tested previously (11.4\%:106) $\left(X^{2}=45.24\right.$ (1) $P$ $<0.05)$. There was no association between residential location and ever tested.

\section{Gaining information about RAPID}

Nearly a third (29.6\%: 338) of RAPID clients gained information about the service through Google and nearly half $(44.1 \%: 82)$ the people who received their first HIV test obtained information about the service through this channel (Table 3). Word of mouth and access

Table 3 Source of information about RAPID and reasons for testing

\begin{tabular}{|c|c|c|}
\hline & All RAPID Clients $(N=1199)$ & First-time testers $n=191(17.1 \%)$ \\
\hline \multicolumn{3}{|l|}{ Hear about the service } \\
\hline Google & $338(29.6)$ & $82(44.1)$ \\
\hline SOPV & $270(23.7)$ & $37(19.9)$ \\
\hline Word of mouth & 209 (18.3) & $33(17.7)$ \\
\hline Dating site/App & $190(16.7)$ & $18(9.7)$ \\
\hline Press & $81(7.1)$ & $5(2.7)$ \\
\hline Facebook & $53(4.6)$ & $11(5.9)$ \\
\hline \multicolumn{3}{|l|}{ Reason for testing ${ }^{a}$} \\
\hline Condomless sex & $371(30.9)$ & $72(37.7)$ \\
\hline Because the results are available in 20 mins & $367(30.6)$ & $55(28.8)$ \\
\hline To have my regular $3 / 6 / 12$ month test & $201(16.8)$ & b \\
\hline Recommended by a friend or other person & $141(11.8)$ & $38(19.9)$ \\
\hline About to enter/finish a relationship & $120(10.0)$ & $23(12.0)$ \\
\hline Dating App Advertisement & $119(9.9)$ & $21(11.0)$ \\
\hline Media Coverage about RAPID or HIV & $75(6.3)$ & $15(7.9)$ \\
\hline Contact with an HIV outreach worker & $73(6.1)$ & $10(5.2)$ \\
\hline Someone I know has been diagnosed & $75(6.3)$ & $15(7.9)$ \\
\hline Perceptions of RAPID Comfort with & (strongly agree/agree) & (strongly agree/agree) \\
\hline More likely to test more frequently at a peer based service & 990 (88.6) & $165(86.4)$ \\
\hline Availability of RHT will increase frequency of testing & $1118(87.3)$ & $159(83.0)$ \\
\hline Overall Satisfaction with a peer based service & $1105(98.8)$ & $191(99.0)$ \\
\hline
\end{tabular}

${ }^{a}$ Respondents could select more than one option

${ }^{\mathrm{b}} \mathrm{Not}$ a valid response for first-time testers

${ }^{\mathrm{c}}$ Not all categories add up to 1199 due to missing data 
through the outreach service at SOPVs were also common sources of information about RAPID.

\section{Reasons for testing}

Condomless sex was the most common reason people identified for accessing the service: nearly one-third of all RAPID clients (30.9\%: 338) and over a third (37.7\%:72) of first-time testers accessed RAPID for this reason. The speed and convenience of the RHT were also identified as key reasons for attending RAPID. Recommendations from friends (11.8\%: all clients; 19.9\%: first-time testers) and entering or exiting a relationship (10\%: all clients; $12 \%$ : first-time testers) were identified by some participants as key reasons for having a test.

\section{Perceptions of RAPID}

Participants were asked to complete a number of questions related to their satisfaction with the RAPID service, particularly in comparison with conventional venepuncture testing. Of those who had previously tested, the vast majority (89.8\%: 832) felt much more comfortable or more comfortable receiving an RHT at RAPID compared to conventional testing. The overwhelming majority (82.5\%: 765) of previous testers also described the experience of receiving an RHT at RAPID as much less stressful and anxiety provoking when compared to conventional testing. The majority of participants, including previous testers and those who had never tested, said they were more likely to increase the frequency of testing given the availability of RHT testing, and access to a peer-based service such as RAPID. The overwhelming majority of participants were satisfied with the RAPID service (Table 3).

\section{Discussion}

This paper highlights the diverse characteristics of people who attended the RAPID testing service during its first year of operation and the overwhelming support and satisfaction of clients accessing the service. The adoption of evidence-based strategies designed to enhance access, including the use of RHT in a convenient, peer-led, community-based service, appear to have supported the Service to achieve its aims of investing in the early detection of HIV and enhancing access to HIV testing, particularly among those who have never tested before.

In highlighting the benefits of the RAPID program, it is clear that drawing conclusions about the Service's effectiveness is limited by the study's reliance on service data and the absence of a control group; however comparisons with other testing services may serve to illustrate the benefits of RAPID's approach. Specifically, the rate of first-time testing at RAPID was consistent with other similar innovative community-based testing services recently established in Sydney and Melbourne [26, 35], but exceeded rates identified in general sexual health clinic samples using the same RHT technology (e.g., 10.1\% reported by Conway and colleagues [36]). This comparison between community-based services such as RAPID, and clinic-based services suggests community offers an effective approach for increasing access to testing, particularly among those who have never tested.

Beyond the strategies employed by RAPID to increase access, a number of factors appear instrumental in increasing awareness and uptake of the Service. The first relates to the way in which people identified RAPID. Nearly a third of all clients, and almost half of first-time users, used the internet to identify a site for testing. A substantially smaller number of people, particularly among first-time testers, accessed RAPID after seeing an advertisement on a dating app. These results highlight the importance of a strong on-line presence, but consistent with broader evidence, suggest limited value in relying on advertising through dating apps as a way to increase testing uptake [37, 38].

Consistent with a broad body of evidence [39-42], the reasons for testing appear to be strongly linked to perceptions of risk of HIV arising from a specific event or incident. Nearly a third of RAPID clients and over a third of those who were testing for the first time, visited RAPID because they had recently had condomless sex, while fewer than $20 \%$ were attending to have their regular test. Immediate perceptions of risk continue to drive testing behaviours within the community [10, 36, 42], while efforts to promote regular testing, in line with the aims of TasP, appear to still have some way to go. Notably, the ability to receive test results quickly and undergo a test that was perceived as 'less stressful' were prominent reasons for accessing RAPID. This finding clearly supports the Service's use of RHT technology as a method to increase access and reinforces the investment made by policy makers in Queensland.

A final observation emerging from this examination of RAPID relates to Medicare eligibility. Nearly a third of first-time testers and a third of those who received a reactive HIV test were ineligible for Medicare. Access to Medicare is limited to Australian citizens and permanent residents: temporary residents on a range of visas including; student, working, bridging or spousal visas are excluded [43]. While it is difficult to provide further details of this group due to the limitations of the available RAPID service data, broader evidence suggests this ineligibility often parallels other characteristics that magnify a person's vulnerability, including constrained financial resources, and social isolation [8, 44]. In providing testing services to all community members, regardless of their Medicare status, RAPID has clearly met its goal of increasing access to testing; however the more 
serious implications of Medicare eligibility for those who tested positive for HIV, but are unable to access subsidised treatment, are undeniable and their circumstances warrant further detailed investigation. Consistent with TasP, RAPID has endeavoured to increase testing rates, but unless everyone who tests positive, including temporary residents, can also access treatment, the TasP strategy will fall short of its goals [43].

\section{Conclusions}

The current paper provides a valuable insight into the diversity of people accessing the RAPID service. While a more detailed consideration is limited by the data, which were gathered to support the RAPID Service and its delivery rather than to inform a wider research agenda, the findings do provide useful insight into the valuable role a community-based testing service, such as RAPID, can play in enhancing access to HIV testing. However, unless policy makers continue to ensure that an accessible service is also matched by access to treatment the commitment to TasP and achieving its goals may fall short.

\section{Additional file}

Additional file 1: Rapid Client Satisfaction form. (PDF 107 kb)

\section{Abbreviations}

ART: Antiretroviral therapy; PLHIV: People living with HIV; QPP: Queensland Positive People; RHT: Rapid HIV testing; SOPV: Sex on premise venues; TasP: Treatment as prevention'; UNAIDS: United Nations Programme on HIV/AIDS

\section{Acknowledgements}

We would like to thank Andrew Redmond, Darren Russell, and Melissa Warner for their valuable feedback on a previous iteration of this paper.

\section{Funding}

We would also like to acknowledge funding and support from the HIV Foundation Queensland.

\section{Availability of data and materials}

Due to ethical concerns, supporting data cannot be made openly available. Further information about the data and conditions to access are available from the corresponding author.

\section{Authors' contributions}

AM analysed the data and wrote the draft of the manuscript, CWL JD, LM, $\mathrm{CH}, \mathrm{AW}$ and LF contributed to the writing of further drafts of the paper. All authors read and approved the final manuscript.

\section{Competing interests}

The authors declare that they have no competing interests.

\section{Consent for publication}

Not applicable.

\section{Ethics approval and consent to participate}

Consent was obtained from all individuals from whom data was collected. Ethics approval for the study was obtained from the Metro North Hospital and Health Service and The University of Queensland Human Research Ethics Committee (Approval No. 2015001063).

\section{Publisher's Note}

Springer Nature remains neutral with regard to jurisdictional claims in published maps and institutional affiliations.

\section{Author details}

${ }^{1}$ The School of Public Health, The University of Queensland, Brisbane, Queensland, Australia. ${ }^{2}$ Centre for Social Research in Health (CSRH), University of New South Wales, NSW, Australia. ${ }^{3}$ Queensland Positive People, Brisbane, Queensland, Australia. ${ }^{4}$ Metro North Public Health Unit, Queensland Health, Brisbane, Queensland, Australia. ${ }^{5}$ School of Social Sciences, Monash University, Melbourne, Victoria, Australia.

Received: 5 November 2016 Accepted: 19 April 2017

Published online: 28 April 2017

References

1. Kretzschmar M, Schim van der Loeff M, Birrell P, De Angelis D, Coutinho R. Prospects of elimination of HIV with test-and-treat strategy. Proc Natl Acad Sci U S A. 2013;110(39):15538-1543.

2. Montaner JS. Treatment as prevention: a double hat-trick. Lancet. 2011; 378(9787):208-9.

3. UNAIDS. 90-90-90 An ambitious treatment target to help end the AIDS epidemic Geneva: Joint United Nations Programme on HIV/AIDS (UNAIDS); 2014.

4. Montaner JG, Lima VD, Harrigan PR, Lourenco L, Yip B, Nosyk B, et al. Expansion of HAART coverage is associated with sustained decreases in HIV/AIDS morbidity, mortality and HIV transmission: the "HIV treatment as prevention" experience in a Canadian setting. PLOS ONE. 2014;9(2):e87872.

5. Ogbuagu $\mathrm{O}$, Bruce RD. Reaching the unreached: treatment as prevention as a workable strategy to mitigate HIV and its consequences in high-risk groups. Curr HIV/AIDS Rep. 2014;11(4):505-12.

6. Flowers P, Knussen C, Li J, McDaid L. Has testing been normalized? An analysis of changes in barriers to HIV testing among men who have sex with men between 2000 and 2010 in Scotland. UK HIV Med. 2013;14(2):92-8.

7. Mao L, Holt M, De Wit J. HIV and STI Testing among gay men. In: De Wit J, Mao L, Adam PCG, Treloar C, editors. Annual report of trends in behaviour 2014 HIV/AIDS, hepatitis and sexually transmissible infections in Australia Sydney. Australia: Centre for Social Research in Health, UNSW: 2014. p. 27-31.

8. Bolsewicz K, Vallely A, Debattista J, Whittaker A, Fitzgerald L. Factors impacting HIV testing: a review - perspectives from Australia, Canada, and the UK. AIDS Care. 2015;27(5):570-80.

9. Lin A-C, Fairley CK, Dutt K, Klassen KM, Chen MY, Fehler G, et al. Testing for HIV among men who have sex with men needs a paradigm shift in Australia, given the minimal increase between 2003 and 2013 in Melbourne. Australia Sex Health. 2015:12(5):373-82.

10. Lorenc T, Marrero-Guillamón I, Llewellyn A, Aggleton P, Cooper C, Lehmann A, et al. HIV testing among men who have sex with men (MSM): systematic review of qualitative evidence. Health Educ Res. 2011;26(5):834-46.

11. Lorenc T, Marrero-Guillamón I, Aggleton P, Cooper C, Llewellyn A, Lehmann A, et al. Promoting the uptake of HIV testing among men who have sex with men: systematic review of effectiveness and cost-effectiveness. Sex Transm Infect. 2011:87(4):272-8.

12. Prestage $G$, Brown $G$, Keen P. Barriers to HIV testing among Australian gay men. Sex Health. 2012;9(5):453-8.

13. Thornton AC, Delpech V, Kall MM, Nardone A. HIV testing in community settings in resource-rich countries: a systematic review of the evidence. HIV Med. 2012;13(7):416-26.

14. Conway DP, Guy R, McNulty A, Couldwell DL, Davies S, Smith DE, et al. Effect of testing experience and profession on provider acceptability of rapid HIV testing after implementation in public sexual health clinics in Sydney. HIV Med. 2015;16(5):280-7.

15. The Kirby Institute. HIV, viral hepatitis and sexually transmissible infections in Australia annual surveillance report 2015. Sydney: The Kirby Institute, UNSW; 2015.

16. Commonwealth of Australia. 2011 National HIV Testing Policy. Canberra: Commonwealth of Australia; 2011.

17. HIV Foundation Queensland: HIV Point of Care Testing Program Brisbane, Australia. http://hivfoundation.org.au/about-us/projects-and-initiatives. Accessed 17 Nov 2015.

18. Remeikis A. Queensland HIV program to expand to Gold Coast. In: The brisbane times. 2015. http://www.brisbanetimes.com.au/queensland/ queensland-hiv-program-to-expand-to-gold-coast-20150613-ghnb6o.html. Accessed 19 Nov 2015. 
19. Hutchinson A, Farnham P, Sansom S, Yaylali E, Mermin J. Cost-effectiveness of frequent HIV testing of high-risk populations in the United States. J Acquir Immune Defic Syndr. 2016;71(3):323-30.

20. Arora D, Maheshwari M, Arora B. Rapid point-of-care testing for detection of HIV and clinical monitoring. ISRN AIDS. 2013;2013:287269.

21. Holt M, Rapid HIV. Testing: a literature review. Australian Feceration of AIDS Organisations: Newtown; 2009.

22. Pottie K, Medu O, Welch V, Dahal GP, Tyndall M, Rader T, et al. Effect of rapid HIV testing on HIV incidence and services in populations at high risk for HIV exposure: an equity-focused systematic review. BMJ Open. 2014;4(12):e006859.

23. Broeckaert L, Challacombe L. Rapid point-of-care HIV testing: a review of the evidence. In: Prevention in Focus. 2015. http://www.catie.ca/en/pif/spring2015/rapid-point-care-hiv-testing-review-evidence. Accessed 20 Jul 2015.

24. Spielberg F, Branson BM, Goldbaum GM, Lockhart D, Kurth A, Rossini A, et al. Choosing HIV counseling and testing strategies for outreach settings: a randomized trial. J Acquir Immune Defic Syndr. 2005;38(3):348-55.

25. Yan H, Zhang R, Wei C, Li J, Xu J, Yang H, et al. A peer-led, communitybased rapid HIV testing intervention among untested men who have sex with men in China: an operational model for expansion of HIV testing and linkage to care. Sex Transm Infect. 2014;90(5):388-93.

26. Knight V, Wand H, Gray J, Keen P, McNulty A, Guy R. Convenient HIV testing service models are attracting previously untested gay and bisexual men: a cross-sectional study. J Acquir Immune Defic Syndr. 2015;69(5):e147-55.

27. Chen MY, Bilardi JE, Lee D, Cummings R, Bush M, Fairley CK. Australian men who have sex with men prefer rapid oral HIV testing over conventional blood testing for HIV. Int J STD AIDS. 2010;21:428-30.

28. Pedrana AR, Guy A, Bowring M, Hellard M, Stoove M. Community models of HIV testing for men who have sex with men (MSM): systematic review 2011. Burnet Institute: Melbourne; 2011.

29. Read TR, Hocking JS, Bradshaw CS, Morrow A, Grulich AE, Fairley CK, et al. Provision of rapid HIV tests within a health service and frequency of HIV testing among men who have sex with men: randomised controlled trial. BMJ. 2013;347:f5086.

30. Webel AR, Okonsky J, Trompeta J, Holzemer WL. A systematic review of the effectiveness of peer-based interventions on health-related behaviors in adults. Am J Public Health. 2010;100(2):247-53.

31. Lambert SM, Debattista J, Bodiroza A, Martin J, Staunton S, Walker R. Effective peer education in HIV: defining factors that maximise success. Sex Health. 2013;10(4):325-31.

32. Minas BC, Giele CM, Laing SC, Bastian L, Burry AW, Sales KJ, et al. Early diagnosis of HIV among men who have sex with men in Western Australia: impact of a peer-led sexually transmissible infection testing service. Sex Health. 2015;12(4):360-3.

33. Worthington C, Myers T. Factors underlying anxiety in HIV testing: risk perceptions, stigma, and the patient-provider power dynamic. Qual Health Res. 2003;13(5):636-55.

34. Mimiaga MJ, Goldhammer H, Belanoff C, Tetu AM, Mayer KH. Men who have sex with men: perceptions about sexual risk, HIV and sexually transmitted disease testing, and provider communication. Sex Transm Dis. 2007;34(2):113-9.

35. Ryan KE, Wilkinson AL, Leitinger D, El-Hayek C, Ryan C, Pedrana A, et al. Characteristics of gay, bisexual and other men who have sex with men testing and retesting at Australia's first shop-front rapid point-of-care HIV testing service. Sex Health. 2016;13(6):560-7.

36. Conway DP, Holt M, Couldwell DL, Smith DE, Davies SC, McNulty A, et al. Barriers to HIV testing and characteristics associated with never testing among gay and bisexual men attending sexual health clinics in Sydney. J Int AIDS Soc. 2015;18(1):20221-8.

37. Wilkinson AL, Pedrana AE, El-Hayek C, Vella AM, Asselin J, Batrouney C, et al. The impact of a social marketing campaign on HIV and sexually transmissible infection testing among men who have sex with men in Australia. Sex Transm Dis. 2016;43(1):49-56.

38. Zou H, Fan S. Characteristics of men who have sex with men who use smartphone geosocial networking applications and implications for HIV interventions: a systematic review and meta-analysis. Arch Sex Behav. 2016:1-10.

39. Beougher SC, Bircher AE, Chakravarty D, Darbes LA, Mandic CG, Neilands TB, et al. Motivations to test for HIV among partners in concordant HIVnegative and HIV-discordant gay male couples. Arch Sex Behav. 2014;44(2): 499-508.

40. Nelson KM, Thiede H, Hawes SE, Golden MR, Hutcheson R, Carey JW, et al. Why the wait? Delayed HIV diagnosis among men who have sex with men. J Urban Health. 2010;87(4):642-55.
41. Dowson L, Kober C, Perry N, Fisher M, Richardson D. Why some MSM present late for HIV testing: a qualitative analysis. AIDS Care. 2012;24(2):204-9.

42. Lui CW, Dean J, Mutch A, Mao L, Debattista J, Lemoire J, Howard C, Whittaker A, Hollingdrake O, Fitzgerald L. HIV testing in men who have sex with men: a follow-up review of the qualitative literature since. AIDS Behav. 2010;2017:1-13.

43. Petoumenos K, Watson J, Whittaker B, Hoy J, Smith D, Bastian L, et al. Subsidized optimal ART for HIV-positive temporary residents of Australia improves virological outcomes: results from the Australian HIV Observational Database Temporary Residents Access Study. J Int AIDS Soc. 2015;18(1):19392.

44. Persson A, Brown G, McDonald A, Korner H. Transmission and prevention of hiv among heterosexual populations in Australia. AIDS Educ Prev. 2014;26(3):245-55.

\section{Submit your next manuscript to BioMed Central and we will help you at every step:}

- We accept pre-submission inquiries

- Our selector tool helps you to find the most relevant journal

- We provide round the clock customer support

- Convenient online submission

- Thorough peer review

- Inclusion in PubMed and all major indexing services

- Maximum visibility for your research

Submit your manuscript at www biomedcentral.com/submit
C Biomed Central 